\title{
Investigation of In vitro Efficacy of Marrubium vulgare L. Essential Oil and Extracts Against Trichomonas vaginalis
}

\author{
Zarifeh Akbari ${ }^{1}$, Dara Dastan ${ }^{2,3}$, Amir Hossein Maghsood ${ }^{1}$, Mohammad Fallah ${ }^{1}$ and Mohammad \\ Matini ${ }^{1, *}$ \\ ${ }^{1}$ Department of Medical Parasitology and Mycology, School of Medicine, Hamadan University of Medical Sciences, Hamadan, Iran \\ ${ }^{2}$ Medicinal Plants and Natural Products Research Center, Hamadan University of Medical Sciences, Hamadan, Iran \\ ${ }^{3}$ Department of Pharmacognosy and Pharmaceutical Biotechnology, School of Pharmacy, Hamadan University of Medical Sciences, Hamadan, Iran \\ "Corresponding author: Department of Medical Parasitology and Mycology, School of Medicine, Hamadan University of Medical Sciences, Hamadan, Iran. Tel: +98-8138380572, \\ Email: matini@umsha.ac.ir
}

Received 2018 February 01; Revised 2018 September 05; Accepted 2018 September 23.

\begin{abstract}
Background: Trichomoniasis is one of the most common nonviral sexually transmitted infections worldwide that its drug-resistant cases are on the rise.

Objectives: The aim of this study was to evaluate the antiprotozoal activity of Marrubium vulgare essential oil and extracts against Trichomonas vaginalis.

Methods: After preparation of essential oil and extracts of M. vulgare, five T. vaginalis isolates were subjected to susceptibility testing after 24 and 48 hours of incubation at $35.5^{\circ} \mathrm{C}$ under aerobic conditions.

Results: The examined essential oil and extracts had potent antitrichomonal activities against T. vaginalis. After 48-hour exposure, the most antitrichomonal activity of $M$. vulgare preparations was related to the essential oil, with a mean minimum inhibitory concentration (MIC) value of $291 \pm 136 \mu \mathrm{g} / \mathrm{mL}$, followed by ethyl acetate $(541 \pm 197 \mu \mathrm{g} / \mathrm{mL})$, methanol (1000 $\pm 0 \mu \mathrm{g} / \mathrm{mL})$, and n-hexane $(1500 \pm 490 \mu \mathrm{g} / \mathrm{mL})$ extracts, in comparison with metronidazole (with MICs ranging from 3.1 to $12.5 \mu \mathrm{g} / \mathrm{mL}$ ).

Conclusions: The findings of this study showed that the compounds of M. vulgare have significant activities against $T$. vaginalis parasite. Therefore, future studies are needed to clear more details about antitrichomonal properties of $M$. vulgare compounds
\end{abstract}

Keywords: Antitrichomonal Agents, Essential Oil, Extract, Metronidazole, Trichomonas vaginalis, Marrubium vulgare

\section{Background}

Trichomonas vaginalis is a flagellated parasite that causes human urogenital trichomoniasis.

Infections with the parasite are one of the most prevalent sexually transmitted infections worldwide (1) so that, according to the WHO report in 2008, 276.4 million cases of the infection occur annually, which are more than the cases of syphilis, gonorrhea, and chlamydia infections (2). Clinical trichomoniasis in females can occur with different intensities, ranging from asymptomatic to severe infections. In addition, the infection is associated with some complications such as adverse pregnancy outcomes, infertility, cervical neoplasia, and most recently, the increased risk of transmission and acquisition of HIV infection $(1,3)$.

Since 1961, metronidazole, a 5-nitroimidazole derivative, has been the main approved drug for the treatment of trichomoniasis in the world. The use of metronidazole is encountering two challenges: First, carcinogenic and teratogenic potential of metronidazole and second, treatment failure of refractory trichomoniasis. The first clinical trichomoniasis resistant to metronidazole was observed in 1962, which has been on the rise (4). The Center for Disease Control and Prevention (CDC) in the United States has estimated that 2 to $5 \%$ of clinical T. vaginalis isolates have some levels of resistance to metronidazole $(5,6)$. Therefore, research on the effectiveness of new pharmaceutical compounds for the treatment of trichomoniasis is necessary.

Traditionally, herbal medicines have been considered as safe drugs for the treatment of many diseases. Moreover, the plant natural compounds are of particular interest due to their broad range of reported activities, such as antimicrobial, anti-inflammatory, antioxidant, and cytotoxic properties (7-9). Lamiaceae (Labiatae) family, with the global distribution and approximately 220 genera and 4000 species, contains important genera in terms of phytomedicine (10). The genus Marrubium (Lamiaceae) is rep- 
resented in Iran by 10 species. Marrubium vulgare is a perennial herb native to Iran with extensive distribution in some areas. This herb is known commonly as white horehound and prescribed in traditional medicine, principally to relieve coughs and treatment of gastrointestinal disorders. Additional properties such as anti-inflammatory, neurosedative, antioxidant, antispasmodic, analgesic, hypolipidemic, and hypoglycemic activities have been attributed to it. Some of the identified phytochemical compounds in M. vulgare are flavonoids, steroids, lactones, alkaloids, tannins, and diterpenoids, especially marrubiin, a bioactive diterpene $(11,12)$.

So far, the effects of a large number of herbal medicines or their natural derivatives have been investigated against pathogenic microbes. In this regard, there is a few evidence of the antimicrobial potential of crude extracts and essential oil of M. vulgare (13-15). Therefore, this study was conducted to assess the in vitro effect of M. vulgare, as a new antitrichomonal agent, on T. vaginalis.

\section{Methods}

\subsection{Plant Material}

The aerial parts of $M$. vulgare were collected in June 2016 from an Avicenna herbs' garden in Hamadan, western Iran. The herb was identified by specialists of the Hamadan Research and Education Center for Agricultural and Natural Resources and deposited as a voucher specimen under number 7950.

\subsection{Preparation of the N-Hexane, Ethyl Acetate, and Methanol Extracts}

The aerial parts of the plant were dried in shade and at ambient temperature. Then, the dried plant's materials were crushed into powders and subjected to extraction by the maceration method (16). Briefly, the plant powder $(100 \mathrm{~g})$ was soaked in three solvents: Methanol, ethyl acetate, and n-hexane $(3 \times 1 \mathrm{~L}$, RT for 72 hours). The extraction continued until reaching the concentration of the extracts through evaporation under vacuum by a rotary evaporator below $40^{\circ} \mathrm{C}$. The obtained light brown gum was stored in a dark airtight container at $4^{\circ} \mathrm{C}$ until use.

\subsection{Preparation of the Essential Oil}

The dried plant's powder (100 g) was subjected to hydrodistillation for three hours by using a Clevenger-type apparatus. The acquired essential oil was dehydrated with anhydrous sodium sulfate and kept in a dark airtight container at $4^{\circ} \mathrm{C}$ until use (17).

\subsection{Isolation and Parasite Culture}

To improve the validity and reliability of the results, instead of one isolate, we used five T. vaginalis isolates. The isolates were grown axenically in TYI-S-33 medium completed with $10 \%$ of heat-inactivated bovine serum and antibiotics. The axenic parasites were applied for susceptibility testing at the parasitology research laboratory of Hamadan University of Medical Sciences from August to September $2016(18,19)$.

\subsection{Preparation of Antitrichomonal Solutions}

The metronidazole solution was prepared by dissolving the drug powder (Sigma Chemical Co. St Louis) in distilled water and sterilized by syringe filter $(0.22 \mu \mathrm{m}$ pore size). Dimethyl sulfoxide (D2650 SIGMA, BioReagent) was used to dissolve the extracts and essential oil. The metronidazole and plant solutions were subjected to serial twofold dilutions in TYI-S-33 medium ranging from 200 $\mu \mathrm{g} / \mathrm{mL}$ to $0.1 \mu \mathrm{g} / \mathrm{mL}$ and from $4000 \mu \mathrm{g} / \mathrm{mL}$ to $62.5 \mu \mathrm{g} / \mathrm{mL}$, respectively (19).

\subsection{Determination of Minimum Inhibitory Concentration}

The minimum inhibitory concentration (MIC) refers to the lowest concentration of the metronidazole, extracts, and essential oils that causes immobilization and death of the parasites after 24 and 48 hours of exposure to the antitrichomonal agents (20). In addition, the concentration of the antitrichomonal agents that caused immobilization and death of $90 \%$ of trichomonad, in comparison with a negative control, was considered as a 90\% inhibitory concentration $\left(\mathrm{IC}_{90}\right)$.

\subsection{Antitrichomonal Susceptibility Assay}

In vitro antitrichomonal susceptibility assay was carried out according to the method recommended by the CDC (20). The susceptibility testing was conducted in 96well flat-bottom microtiter plates, as follows: First, the respective concentrations of the antitrichomonal agents were prepared and then, a certain volume of the isolated parasites in the logarithmic phase of growth $\left(1 \times 10^{5}\right.$ cells $/ \mathrm{mL}$ ) was added to the wells of the microtiter test plates and incubated at $35.5^{\circ} \mathrm{C}$. After 24 and 48 hours of incubation, the test plates were examined to determine the MICs of the antitrichomonal agents by an inverted microscope. All susceptibility tests were done aerobically in duplicate and repeated three independent times under the sterile condition and against a negative control (without any extracts or essential oil), a positive control (with metronidazole), and a DMSO control. 


\subsection{Data Analysis}

Data were presented as MIC values, $\geq \mathrm{IC}_{90}$ values, and means \pm standard deviation (SD) and analyzed by SPSS statistical software, version 16. The mean MIC values were compared by nonparametric tests, Friedman's test, and Wilcoxon test and $\mathrm{P}$ values of less than 0.05 were considered statistically significant.

\section{Results}

In this study, the in vitro antitrichomonal activity of $M$. vulgare essential oil and extracts was investigated against five clinical T. vaginalis isolates. In total, for each herbal preparation, 30 series of susceptibility tests were conducted and the mean MIC values were compared with each other and with that of metronidazole as a standard drug.

All investigated extracts and the essential oil had potential antitrichomonal activity by inhibition of motility and death of the parasite after 24 and 48 hours of exposure. Table 1 shows the efficacy of the herbal agents after 24-hour incubation, with the highest effect on the parasite being related to the essential oil of M. vulgare. After 48-hour incubation, the effect of herbal agents increased and the essential oil of M. vulgare was detected as the most effective antitrichomonal agent with a mean MIC value of $291 \pm 136$ $\mu \mathrm{g} / \mathrm{mL}$, followed by ethyl acetate extract $(541 \pm 197 \mu \mathrm{g} / \mathrm{mL})$, methanol extract $(1000 \pm 0 \mu \mathrm{g} / \mathrm{mL})$, and $\mathrm{n}$-hexane extract $(1500 \pm 490 \mu \mathrm{g} / \mathrm{mL})(\mathrm{P}<0.001)$ (Table 2). Friedman's test analysis showed significant differences between the antiTrichomonas agent groups $(\mathrm{P}<0.001)$ although Wilcoxon test revealed no significant difference between the effects of methanol and hexane extracts on T. vaginalis isolates ( $\mathrm{P}$ $<0.08)$.

In vitro drug susceptibility testing of the parasite showed that all isolates were sensitive to metronidazole and after 48-hour incubation, the metronidazole MICs were in the range of 3.1 to $12.5 \mu \mathrm{g} / \mathrm{mL}$ (Table 2 ).

\section{Discussion}

Drug resistance of pathogenic microorganisms is a significant public health problem that is on the rise. Metronidazole is the most common drug used for the treatment of trichomoniasis and treatment failure with metronidazole has been reported and estimated to be up to $10 \%$ in the United States (21).

In the present study, we investigated the antitrichomonal activity of extracts and essential oil of M. vulgare in comparison with metronidazole. All extracts and essential oil had potent antitrichomonal activities dose- and incubation time-dependently. The tested herbal preparations were able to kill $100 \%$ of the parasites at certain concentrations and various effective concentrations were statistically significant.

Among the tested herbal preparations on the T. vaginalis isolates, essential oil of M. vulgare was the most effective antiprotozoal compound with the lowest and mean MIC values of 125 and $291 \pm 136 \mu \mathrm{g} / \mathrm{mL}$, respectively, after 48 hour incubation. Whereas, the least antiprotozoal effect was related to the n-hexane extract, with the lowest MIC of $1000 \mu \mathrm{g} / \mathrm{mL}$ and mean MIC of $1500 \pm 490 \mu \mathrm{g} / \mathrm{mL}$. A statistically significant difference was observed between the results of the herbal preparations assay and those of the metronidazole susceptibility test, with a mean MIC value of $5.8 \pm 3.9 \mu \mathrm{g} / \mathrm{mL}$. The results indicate the significant effects of the herbal preparations on the parasite.

The antiprotozoal activity of the compounds was related to their concentrations. After 48 hours of exposure and at a minimum concentration of $62.5 \mu \mathrm{g} / \mathrm{mL}$, M. vulgare essential oil was able to kill at least $90 \%$ of the parasites in susceptibility testing of two isolates. In addition, the other factor that influenced the antiprotozoal activity of the compounds was exposure time. Follow-up microtiter plate tests were performed for up to 72 hours and the MIC and $\mathrm{IC}_{90}$ values of the herbal preparations reduced by longer exposure time (data not shown). In this study, we emphasized the 48-h MIC values of antitrichomonal agents based on the CDC susceptibility testing protocol (20).

The antiprotozoal activity of M. vulgare found in this study can be related to the bioactive phytochemical components such as flavonoids, alkaloids, steroids, tannins, and diterpenoids (22). A few reports are available about the antibiotic activity of M. vulgare components. The antimicrobial potency of $M$. vulgare on some pathogenic Grampositive bacteria and Botrytiscinerea fungi was reported by Zarai et al. In this study, the antibacterial MIC values and the antifungal inhibition zones of the essential oil were in the range of 1120 - $2600 \mu \mathrm{g} / \mathrm{mL}$ and 6.6 - $25.2 \mathrm{~mm}$, respectively (13). Molluscicidal and mosquitocidal potency of $M$. vulgare has been reported by Salama et al. Biomphalaria alexandrina adult snail was sensitive to the essential oil with $\mathrm{LC}_{50}$ and $\mathrm{LC}_{90}$ values of 50 and $100 \mathrm{ppm} / 3 \mathrm{~h}$, respectively. After 24 hours, the ovicidal activity of the essential oil on B. alexandrina was at $200 \mathrm{ppm}$. In addition, the mosquitocidal potency of $M$. vulgare essential oil was reported on Culex pipiens larvae $\left(\mathrm{LC}_{50}=100\right.$ and $\mathrm{LC}_{90}=200$ $\mathrm{ppm} / 12 \mathrm{~h})$ and pupae $\left(\mathrm{LC}_{50}=200\right.$ and $\left.\mathrm{LC}_{90}=400 \mathrm{ppm} / 12 \mathrm{~h}\right)$ (23). Ramos-Guerra and colleagues showed the antiprotozoal activity of M. vulgare extracts against two intestinal protozoa metabolically close to T. vaginalis, Entamoeba histolytica and Giardia lamblia. The methanol and acetone extracts of M. vulgare were able to inhibit 50\% of the growth 


\begin{tabular}{|c|c|c|c|c|c|c|}
\hline \multirow{2}{*}{$\begin{array}{l}\text { Essential Oil, Extracts, } \\
\text { and Drug }\end{array}$} & \multicolumn{3}{|c|}{$\mathrm{IC}_{90}{ }^{\mathrm{b}}$ Value, $\mu \mathrm{g} / \mathrm{mL}$} & \multicolumn{3}{|c|}{ MIC $^{\mathbf{c}}$ Value, $\mu \mathrm{g} / \mathrm{mL}$} \\
\hline & Lowest & Highest & $\operatorname{Mean}^{\mathrm{a}} \pm \mathrm{SD}$ & Lowest & Highest & Mean $^{\mathrm{a}} \pm S D$ \\
\hline Essential oil & 125 & 250 & $175 \pm 62$ & 250 & 500 & $350 \pm 124$ \\
\hline Ethyl acetate extract & 500 & 500 & $500 \pm 0$ & 1000 & 1000 & $1000 \pm 0$ \\
\hline Methanol extract & 1000 & 2000 & $1133 \pm 345$ & 2000 & 4000 & $2266 \pm 691$ \\
\hline Hexane extract & 500 & 2000 & $1250 \pm 468$ & 2000 & 4000 & $2533 \pm 899$ \\
\hline Metronidazole & 1.6 & 12.5 & $5.5 \pm 3.8$ & 3.1 & 25 & $11.5 \pm 7.9$ \\
\hline
\end{tabular}

${ }^{\mathrm{a}}$ The mean of 30 values of susceptibility testing obtained from three independent assays performed in duplicate.

${ }^{\mathrm{b}}$ The concentration that causes $\geq 90 \%$ trichomonads growth inhibition.

${ }^{\mathrm{c}}$ The concentration that causes the death of $100 \%$ trichomonads.

\begin{tabular}{|c|c|c|c|c|c|c|}
\hline \multirow{2}{*}{$\begin{array}{l}\text { Essential Oil, Extracts, } \\
\text { and Drug }\end{array}$} & \multicolumn{3}{|c|}{ IC $_{90}{ }^{\text {b }}$ Value, $\mu \mathrm{g} / \mathrm{mL}$} & \multicolumn{3}{|c|}{ MIC $^{\mathrm{C}}$ Value, $\mu \mathrm{g} / \mathrm{mL}$} \\
\hline & Lowest, & Highest & $\operatorname{Mean}^{\mathrm{a}} \pm S D$ & Lowest & Highest & $\operatorname{Mean}^{\mathrm{a}} \pm \mathbf{S D}$ \\
\hline Essential oil & 62.5 & 250 & $145 \pm 68$ & 125 & 500 & $291 \pm 136$ \\
\hline Ethyl acetate extract & 250 & 500 & $375 \pm 127$ & 250 & 1000 & $541 \pm 197$ \\
\hline Methanolic extract & 500 & 500 & $500 \pm 0$ & 1000 & 1000 & $1000 \pm 0$ \\
\hline Hexanic extract & 500 & 1000 & $716 \pm 252$ & 1000 & 2000 & $1500 \pm 490$ \\
\hline Metronidazole & 0.4 & 6.2 & $1.3 \pm 1.5$ & 3.1 & 12.5 & $5.8 \pm 3.9$ \\
\hline
\end{tabular}

${ }^{\mathrm{a}}$ The mean of 30 values of susceptibility testing obtained from three independent assays performed in duplicate.

${ }^{b}$ The concentration that causes $\geq 90 \%$ trichomonads growth inhibition.

${ }^{\mathrm{c}}$ The concentration that causes the death of $100 \%$ trichomonads.

of E. histolytica $\left(\mathrm{IC}_{50}=12\right.$ and $\left.7 \mu \mathrm{g} / \mathrm{mL}\right)$ and $\mathrm{G}$. lamblia $\left(\mathrm{IC}_{50}=\right.$ 34 and $90 \mu \mathrm{g} / \mathrm{mL})$, respectively, after 72 hours of exposure to the extracts (14). In the mentioned study, the antiprotozoal activity of M. vulgare extracts was shown to be in accordance with our survey. However, the extracts of M. vulgare were more effective against E. histolytica and G. lamblia than against $T$. vaginalis, which may be due to reporting $\mathrm{IC}_{50}$ after 72-hour exposure.

So far, the efficacy of some medicinal herbs has been explored against $T$. vaginalis parasite that some of them will be mentioned. In the investigation of the efficacy of two Lavandula species on some flagellated protozoa conducted by Moon et al. L. angustifolia and L. intermedia essential oils were able to eliminate $T$. vaginalis trophozoite at concentrations of 1 and $0.5 \%$ after 20 minutes of exposure. However, both essential oils at concentrations of $0.1 \%$ were effective against the parasite within 65 to 80 minutes of exposure time (24). The antitrichomonal activity of 22 methanolic extracts of Mexican medicinal herbs was investigated by Calzada and colleagues and the extracts of Carica papaya and Cocos nucifera were found the most effective antitrichomonal agents with $\mathrm{IC}_{50}$ values of 5.6 and $5.8 \mu \mathrm{g} / \mathrm{mL}$, respectively, followed by Bocconia frutescens, Geranium mexicanum, and Lygodiumvenustum with $\mathrm{IC}_{50}$ values between 30.9 and $60.9 \mu \mathrm{g} / \mathrm{mL}$, in comparison with the metronidazole $\mathrm{IC}_{50}$ value $(0.037 \mu \mathrm{g} / \mathrm{mL})(25)$. In a randomized controlled clinical trial, the antitrichomonal potency of Mentha crispa was studied in comparison with secnidazole, another member of the 5-nitroimidazole group. The cure rate of patients with trichomoniasis after receiving a single dose of secnidazole (2000 $\mathrm{mg}$ ) was $96.6 \%$ while, in another patient group treated with a single dose of $M$. crispa (24 mg), it was $90 \%$. In this study, the difference between the cure rates of the two antitrichomonal agents was not statistically significant $(P=0.6120)(26)$. Ertabaklar et al. examined Arbutus unedo leaf extracts against $T$. vaginalis during 48 hours of incubation. Among aqueous, ethanolic, ethyl acetate, and n-hexane extracts, only was able ethyl acetate extract to inhibit 100\% of the growth of the parasite at a concentration of $500 \mu \mathrm{g} / \mathrm{mL}$ (27). An encouraging result has been reported about the efficacy of Allium hirtifolium (Persian shallot) against T. vaginalis. Taran and colleagues studied the Persian shallot hydroalcoholic and dichloromethane extract against a flagellate parasite after 48-hour exposure. The MIC values of the hydroalcoholic and dichloromethane extracts were 10 and 5 $\mu \mathrm{g} / \mathrm{mL}$, respectively, in comparison with the MIC value of metronidazole ( $2 \mu \mathrm{g} / \mathrm{mL})$ (28). Organosulfur compounds such as allicin and ajoene are assumed responsible for the antimicrobial activity of Allium species (29). Some other 
medicinal plants with antitrichomonal activities that have been reported include Eucalyptus species, Myrtus Communis, Artemisia aucheri, Zataria multiflora, Ferula assafoetida, Allium sativum, Mentha piperita, Salvia officinalis, Tanacetum Parthenium, and Taxus baccata (30).

\subsection{Conclusion}

The results of the present study showed that the essential oil and the extracts of M. vulgare have potential activities against $T$. vaginalis parasite although complementary studies are needed to fractionate and evaluate the efficacy of bioactive components of M. vulgare against T. vaginalis.

\section{Acknowledgments}

The authors thank the Vice-Chancellor for Research and Technology, Hamadan University of Medical Sciences, for their financial support (Project No. 9409034747).

\section{Footnotes}

Conflict of Interests: The authors declare that they have no conflict of interests to disclose.

Funding/Support: Hamadan University of Medical Sciences funded the study.

\section{References}

1. Schwebke JR, Burgess D. Trichomoniasis. Clin Microbiol Rev. 2004;17(4):794-803. table of contents. doi: 10.1128/CMR.17.4.794803.2004. [PubMed: 15489349]. [PubMed Central: PMC523559].

2. World Health Organization. Global incidence and prevalence of selected curable sexually transmitted infections-2008. Geneva; 2012. Available from: http://www.who.int/reproductivehealth/publications/rtis/ stisestimates/en/index.html.

3. Petrin D, Delgaty K, Bhatt R, Garber G. Clinical and microbiological aspects of Trichomonas vaginalis. Clin Microbiol Rev. 1998;11(2):30017. doi: 10.1128/CMR.11.2.300. [PubMed: 9564565]. [PubMed Central: PMC106834].

4. Robinson SC. Trichomonal vaginitis resistant to metranidazole. Can Med Assoc J. 1962;86(14):665. [PubMed: 20327097]. [PubMed Central: PMC1849337].

5. Schmid G, Narcisi E, Mosure D, Secor WE, Higgins J, Moreno H. Prevalence of metronidazole-resistant Trichomonas vaginalis in a gynecology clinic. J Reprod Med. 2001;46(6):545-9. doi: 10.1097/00006254200111000-00015. [PubMed: 11441678].

6. Workowski KA, Berman SM. Centers for Disease Control and Prevention Sexually Transmitted Disease Treatment Guidelines. Clin Infect Dis. 2011;53 Suppl 3:S59-63. doi: 10.1093/cid/cir694. [PubMed: 22080270].

7. Dastan D, Salehi P, Reza Gohari A, Ebrahimi SN, Aliahmadi A, Hamburger M. Bioactive sesquiterpene coumarins from Ferula pseudalliacea. Planta Med. 2014;80(13):1118-23. doi: 10.1055/s-0034-1382996. [PubMed: 25137575].

8. Mohammadi M, Yousefi M, Habibi Z, Dastan D. Chemical composition and antioxidant activity of the essential oil of aerial parts of Petasites albus from Iran: A good natural source of euparin. Nat Prod Res. 2012;26(4):291-7. doi: 10.1080/14786410903374819. [PubMed: 21416453].
9. Dastan D, Salehi P, Ghanati F, Gohari AR, Maroofi H, Alnajar N. Phytotoxicity and cytotoxicity of disesquiterpene and sesquiterpene coumarins from Ferula pseudalliacea. Ind Crops Prod. 2014;55:43-8. doi: 10.1016/j.indcrop.2014.01.051.

10. Naghibi F, Mosaddegh M, Mohammadi Motamed S, Ghorbani A. Labiatae family in folk medicine in Iran: From ethnobotany to pharmacology. Iran J Pharm Res. 2010;2(4):63-79.

11. Morteza-Semnani K, Saeedi M, Babanezhad E. The essential oil composition of marrubium vulgare L. from Iran. J Essent Oil Res. 2008;20(6):488-90. doi:10.1080/10412905.2008.9700065.

12. Paula de Oliveira A, Santin JR, Lemos M, Klein Junior LC, Couto AG, Meyre da Silva Bittencourt C, et al. Gastroprotective activity of methanol extract and marrubiin obtained from leaves of Marrubium vulgare L. (Lamiaceae).JPharm Pharmacol.2011;63(9):1230-7. doi: 10.1111/j.2042-7158.2011.01321.x. [PubMed: 21827496].

13. Zarai Z, Kadri A, Ben Chobba I, Ben Mansour R, Bekir A, Mejdoub H, et al. The in-vitro evaluation of antibacterial, antifungal and cytotoxic properties of Marrubium vulgare L. essential oil grown in Tunisia. Lipids Health Dis. 2011;10:161. doi: 10.1186/1476-511X-10-161. [PubMed: 21936887]. [PubMed Central: PMC3196909].

14. Ramos-Guerra MC, Mata-Cárdenas BD, Vargas-Villarreal J, SampayoReyes A, González-Salazar F, Morales-Vallarta M, et al. In vitro activity of organic leaf/stem extracts from Marrubium vulgare and Mentha spicata against Entamoeba histolytica and Giardia lamblia. Pharmacology. 2007;1:108-12.

15. Masoodi MH, Ahmed B, Zargar IM, Khan SA, Khan S, Singh P. Antibacterial activity of whole plant extract of Marrubium vulgare. Afr JBiotechnol. 2008;7(2):86-7.

16. Abdali E, Javadi S, Akhgari M, Hosseini S, Dastan D. Chemical composition and biological properties of Satureja avromanica Maroofi. J Food Sci Technol. 2017;54(3):727-34. doi: 10.1007/s13197-017-2512-0. [PubMed: 28298686]. [PubMed Central: PMC5334231].

17. Dastan D, Salehi P, Maroofi H. Chemical composition, antioxidant, and antimicrobial activities on laserpitium carduchorum hedge \& lamond essential oil and extracts during various growing stages. Chem Biodivers. 2016;13(10):1397-403. doi: 10.1002/cbdv.201600087. [PubMed: 27450544].

18. Matini M, Rezaie S, Mohebali M, Maghsood A, Rabiee S, Fallah M, et al. Prevalence of trichomonas vaginalis infection in Hamadan city, Western Iran. Iran J Parasitol.2012;7(2):67-72. [PubMed: 23109948]. [PubMed Central: PMC3469190].

19. Matini M, Maghsood AH, Mohebali M, Rabiee S, Fallah M, Rezaie S, et al. In vitro susceptibility of Iranian isolates of trichomonas vaginalis to metronidazole. Iran J Parasitol. 2016;11(1):46-51. [PubMed: 27095968]. [PubMed Central: PMC4835469].

20. Schwebke JR, Barrientes FJ. Prevalence of Trichomonas vaginalis isolates with resistance to metronidazole and tinidazole. Antimicrob Agents Chemother. 2006;50(12):4209-10. doi: 10.1128/AAC.00814-06. [PubMed: 17000740]. [PubMed Central: PMC1693974].

21. Dunne RL, Dunn LA, Upcroft P, O’Donoghue PJ, Upcroft JA. Drug resistance in the sexually transmitted protozoan Trichomonas vaginalis. Cell Res. 2003;13(4):239-49. doi: 10.1038/sj.cr.7290169. [PubMed: 12974614].

22. Bero J, Frederich M, Quetin-Leclercq J. Antimalarial compounds isolated from plants used in traditional medicine. J Pharm Pharmacol. 2009;61(11):1401-33. doi: 10.1211/jpp/61.11.0001. [PubMed: 19903367].

23. Salama MM, Taher EE, El-Bahy MM. Molluscicidal and mosquitocidal activities of the essential oils of thymus capitatus hoff. Et link. and marrubium vulgare L. Rev Inst Med Trop Sao Paulo. 2012;54(5):281-6. doi: 10.1590/S0036-46652012000500008. [PubMed: 22983292].

24. Moon T, Wilkinson JM, Cavanagh HM. Antiparasitic activity of two Lavandula essential oils against Giardia duodenalis, Trichomonas vaginalis and Hexamita inflata. Parasitol Res. 2006;99(6):722-8. doi: 10.1007/s00436-006-0234-8. [PubMed:16741725]. 
25. Calzada F, Yepez-Mulia L, Tapia-Contreras A. Effect of Mexican medicinal plant used to treat trichomoniasis on Trichomonas vaginalis trophozoites. J Ethnopharmacol. 2007;113(2):248-51. doi: 10.1016/j.jep.2007.06.001. [PubMed: 17628366].

26. Moraes ME, Cunha GH, Bezerra MM, Fechine FV, Pontes AV, Andrade WS, et al. Efficacy of the Mentha crispa in the treatment of women with Trichomonas vaginalis infection. Arch Gynecol Obstet. 2012;286(1):125-30. doi: 10.1007/s00404-012-2251-4. [PubMed: 22350328].

27. Ertabaklar H, Kivcak B, Mert T, Ozensoy Toz S. In vitro activity of Arbutus unedo leaf extracts against Trichomonas vaginalis trophozoites. Turkiye Parazitol Derg. 2009;33(4):263-5. [PubMed: 20101573].
28. Taran M, Rezaeian M, Izaddoost M. In vitro antitrichomonas activity of Allium hirtifloium (Persian Shallot) in comparison with metronidazole. Iran J Public Health. 2006;35(1):92-4.

29. Mikaili P, Maadirad S, Moloudizargari M, Aghajanshakeri S, Sarahroodi S. Therapeutic uses and pharmacological properties of garlic, shallot, and their biologically active compounds. Iran J Basic Med Sci. 2013;16(10):1031-48. [PubMed: 24379960]. [PubMed Central: PMC3874089].

30. Sharafi SM, Yousefi M, Yousefi HA, Asghari G, Darani HY. In vitro effects of various plants extracts on the growth of Trichomonas vaginalis. Infect Disord Drug Targets. 2013;13(5):322-7. doi: 10.2174/1871526514666140321111329. [PubMed: 24712672]. 